\title{
Testicular biopsies in infertility and correlation with clinical and laboratory features
}

\author{
Priscilla Babu', Vivi M Srivastava ${ }^{2}$ \\ ${ }^{1}$ Resident, ${ }^{2}$ Professor and Head, Department of General Pathology, Christian Medical College, Vellore, Tamil Nadu, India
}

Background: With advances in assisted reproductive techniques management of infertility is changing at a very fast pace. Although minimally invasive techniques such as testicular sperm aspiration and micro-dissection testicular sperm extraction (microTESE) are gaining increased acceptance due to their minimally invasive nature the importance of testicular biopsy can not be overemphasized. Testicular biopsy provides a more accurate picture of testicular pathology and helps in identifying conditions such as hypospermatogenesis, which may not be evident on microTESE. Aims and Objectives: The aim of the study was to study the histopathology of testicular tissue in infertile males and to correlate the histopathologic findings with clinical features and relevant laboratory findings. Materials and Methods: Seventy patients with male infertility who had undergone testicular biopsies were included in this study on the basis of a predefined inclusion and exclusion criteria. The study was conducted in the department of general pathology, Christian medical college Vellore. Demographic details and history were recorded in all patients. Hormonal profile, Histopathological analysis was done in all the cases. Chromosomal analysis and $\mathrm{Y}$ chromosomal microdeletion studies were done in selected cases. Results: Among the 70 patients evaluated, semen analysis revealed azoospermia in all but four cases. The most commonly affected age group was found to be between 31 and 35 years $(44.29 \%)$. The mean age of the patients was found to be $33.71 \pm 5.56$ years. Only $37.14 \%$ of our patients had normal testicular volumes and $66(94.29 \%)$ patients had azoospermia. The majority of the patients (64.29\%) had high FSH values (>11 mlU/ml). On histopathological examination, the basement membrane was thickened (more than 0.40 microns) in 26 cases $(37.14 \%)$. On analysis of seminiferous tubules, maturation arrest was the most common abnormality $(40 \%)$ followed by Sertoli cells only $(30 \%)$ and hypospermatogenesis $(15.71 \%)$. Maturation arrest was most commonly seen at the stage of primary spermatocyte $(22.86 \%)$. Karyotyping was done only in 24 selected cases. Out of 24 patients, 23 patients had normal chromosomal numbers $(95.83 \%)$ whereas one patient had a missing $\mathrm{Y}$ chromosome (4.17\%). $\mathrm{Y}$ chromosome microdeletion studies showed abnormalities in three patients consisting of AZFa,b,c in two patients $(8.33 \%)$ and AZFb deletion in $1(4.77 \%)$ patient. Conclusion: Testicular biopsy is an important investigation in patients with male factor infertility. It not only does help in accurate diagnosis but also can help in sperm extraction for usage in in vitro fertilization and intracytoplasmic sperm injection.

Key words: Assisted reproductive techniques; Follicle-stimulating hormone; Histopathology of the testis; Testicular biopsy

\section{INTRODUCTION}

Infertility is a commonly encountered problem in approximately $15 \%$ of couples who wish to conceive. The causes are varied and can be divided as endogenous and exogenous with respect to the testicular origin. ${ }^{1}$ The pre-

\section{Access this article online}

\section{Website:}

http://nepjol.info/index.php/AJMS DOI: $10.3126 /$ ajms.v13i3.40873

E-ISSN: 2091-0576

P-ISSN: 2467-9100

Copyright (c) 2022 Asian Journal of Medical Sciences

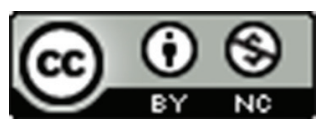

This work is licensed under a Creative Commons Attribution-NonCommercial 4.0 International License. 
It has been observed that there is a progressive decline in the number of testicular biopsies performed, in centers all over the world and in our country. The work-up of a patient seeking help for infertility involves recording of the history and clinical findings and an array of laboratory tests. Physical parameters such as body mass index (BMI), secondary sexual characteristics, including testicular volume are assessed to exclude Klinefelter syndrome or other disorders of sexual development. ${ }^{3}$ Laboratory investigation usually done in these cases include a semen analysis and a hormonal profile to estimate the levels of Follicle-Stimulating Hormone (FSH), Luteinizing hormone (LH), Testosterone, and Prolactin. ${ }^{4}$ Although most centers perform the entire hormone panel, it may not be feasible in all centers.

If the semen analysis shows azoospermia, it is essential to determine whether the cause is primarily testicular failure or merely due to blockage in the passage of otherwise normal, motile sperms. A needle aspiration technique known as testicular sperm aspiration (TESA) is performed to retrieve sperms provided the testicular volume is adequate. The advantages of TESA are that this procedure does not require expertise and can, therefore, be done even by internists. ${ }^{5}$ However, for the same reason, it must be remembered that the yield of sperms may be poor. If sperms are not obtained by TESA, or if the testicular volume is low, either a procedure called microdissection testicular sperm extraction (microTESE) or a testicular biopsy is done. ${ }^{6}$ In microTESE, the testicular tissue is examined at $\times 25$ magnification, and the presence or absence of sperms is confirmed. MicroTESE or testicular biopsy is attempted depending upon the facilities available. MicroTESE has the advantage that small amount of tissue can be surgically removed with precision ensuring a better yield of sperms and better preservation of testicular function, also, facilitating freezing this tissue for assisted reproductive techniques (ART). ${ }^{7}$

Testicular biopsy provides a larger amount of tissue for examination but cannot be preserved for use in ART. These procedures are also done to determine the condition of the testicular tubules in non-obstructive azoospermia when the presence of sperms is not guaranteed. ${ }^{8}$ With the options of TESA which is less invasive and microdissection testicular sperm extraction microTESE, the number of testicular biopsies being done for infertility has declined. However, the importance of histological assessment lies in providing a more accurate picture of testicular pathology and identifying conditions such as hypospermatogenesis, which may not be evident on microTESE, or Intratubular Germ Cell Neoplasm which may be an incidental finding. ${ }^{9}$ The importance of an accurate histologic assessment lies in tailoring treatment and further management and counseling accordingly. Depending on the presence of mature sperms in the biopsy, further sperm extraction can be planned. ${ }^{10}$

We conducted this study to analyze histopathology of testicular tissue in men with azoospermia, and correlate the findings with clinical features, serum levels of sex hormones, and karyotyping.

\section{Aims and objectives}

To study the histopathology of testicular tissue in men with azoospermia, and correlate the findings with clinical features, serum levels of sex hormones and karyotype and Y chromosome micro-deletion status when available.

\section{MATERIALS AND METHODS}

Seventy male patients being treated for infertility were included in this study on the basis of a predefined inclusion and exclusion criteria. The study was conducted in the department of General Pathology Christian Medical College. The institutional ethical committee duly approved the study. The duration of the study was 2 years from January 2018 to June 2020. An informed and written consent was obtained from the study. All patients undergoing testicular biopsies for evaluation of infertility were included in this study. The age group selected for this study was from 20 to 50 years. Patients above 50, those who refused consent and those who had a history of any significant testicular pathology including neoplastic diseases were excluded from the study.

Demographic details such as age, weight, height BMI of all the patients were recorded. A detailed history was taken particularly in respect to the presence of any significant illness in past or the presence of any systemic illness. History of any addiction was asked for and recorded. A thorough general and systemic examination were done. Testicular volume was also assessed and recorded. Semen analysis, serum FSH, LH, serum testosterone, and prolactin levels were done in all the cases. Testicular volumes were categorized to be normal (15-25 ml); sub-normal (12-15) or critically low $(<12 \mathrm{ml})$.

All patients had undergone open biopsies. Under local anesthesia, a scrotal incision was made and the tunica albuginea was opened. Gentle pressure was applied so as to allow tissue to protrude out from the incision. This tissue was excised and immediately immersed in Bouin's fixative for $12 \mathrm{~h}$. The tissue was then immersed in toluidine buffer solution following which it was transferred to graded alcohol for routine processing and later embedding in paraffin. 
Forty-five slides were prepared from 5-micron sections and stained using hematoxylin and eosin. Periodic acid Schiff staining was done to highlight thickening of the basement membrane and Ziehl-Neelsen staining was used to identify acid-fast bacilli.

Microscopy was done and the number of tubules was counted using the $\times 10$ magnification.

Sections containing 20 or more seminiferous tubules were considered adequate for histological examination. The morphology of the tubules and interstitium were studied using the high-power objective $(\times 40)$.

The following parameters were studied histologically:

1. Number of tubules.

2. Tubule diameter.

3. Tubular basement membrane thickness.

4. Presence of tubular atrophy and/or hyalinization.

5. Prominence of Sertoli cells.

6. Degree of maturation of germ cells.

7. Interstitial cellularity and vascularity.

8. Number of Leydig cells.

9. Presence or absence of fibrosis.

Morphometry was used to estimate tubule diameter and basement membrane thickness, using Cellsens image analysis software. Each slide was assessed at $\times 25$ magnification and five such fields were arbitrarily selected, for calculating the diameter. A mean was calculated for each case. The tubule diameter was considered normal if it was found to be $\geq 150$ microns.

The basement membrane thickness was considered to be normal if $\leq 0.40$ microns (normal range $0.3-0.4$ microns). Based on the distribution of Leydig cells in the interstitium different patterns were observed, normal Leydig cells, Leydig cell clusters ( $<10$ cells), Leydig cell hyperplasia (if more than 10-20 cells per cluster).

Conventional cytogenetic analysis (peripheral blood karyotyping) was done using standard protocols. Briefly, peripheral blood was collected using sterile precautions in a sodium heparin vacutainer and cultured for $72 \mathrm{~h}$ after phytohemagglutinin-stimulation, following which the chromosomes were harvested. The harvested chromosomes were banded (stained) with Leishman stain following treatment with trypsin (trypsin G-banding). At least $20 \mathrm{G}$-banded metaphases were analyzed for each patient.

Fluorescence in situ hybridization (FISH) analysis was performed when required to better describe an abnormality. The probes used were as follows: a whole Y chromosome paint, probes to the centromeres of chromosomes $\mathrm{X}$ and $\mathrm{Y}$, and locus-specific probes for the SRY gene and the terminal ends of both arms of chromosome 1 (bands 1p36 and 1q44). The probes were obtained from Abbot Vysis (Illinois, U.S.A. For FISH analysis, 100 interphase cells and 20 metaphases were studied. Standard protocols were used for both karyotyping and FISH.

Conventional cytogenetic analysis and FISH analysis were done using Zeiss Axioskop and AxioImager microscopes at $\times 100$ magnification and automated karyotyping system (Ikaros and Isis, MetaSystems GmbH, Altlussheim, Germany). Results were reported in accordance with the International System for Human Cytogenetic Nomenclature. Y chromosome microdeletion analysis was done on peripheral blood collected in EDTA using a multiplex polymerase chain reaction in accordance with the guidelines of the European Academy of Andrology and the European Molecular Genetics Quality Network.

The statistical analysis was done using SSPS 21.0 software and $\mathrm{P}<0.05$ was taken as statistically significant.

\section{RESULTS}

There were 70 patients who underwent testicular biopsies for investigation of infertility. Only one testis was biopsied in all but two patients. Two patients had bilateral biopsies done. All other patients had only biopsy of one side. The analysis of age groups of the studied cases showed that the patients ranged from 23 to 47 years of age, with a mean age of $33.71 \pm 5.56$ years. The majority of patients (44\%) belonged to the age group of 31-35 years. Mean age of the studied cases was found to be $33.71 \pm 5.56$ years (Table 1).

Patients were categorized into three groups according to the testicular volume. which was assessed clinically. These categories were normal (15-25 ml), subnormal (12-15) and critically low $(<12 \mathrm{ml})$. Testicular volumes were available for 44 of our patients and ranged from $1.5 \mathrm{ml}$ to $20 \mathrm{ml}$ (mean $11 \mathrm{ml}$ ). Only $37.14 \%$ of our patients had normal testicular volumes. The majority $(55 \%)$ had critically low volumes (Figure 1).

\begin{tabular}{lcc}
\multicolumn{3}{l}{ Table 1: Mean age of the studied cases } \\
\hline Age (years) & Number of patients & Percentage \\
\hline $21-25$ & 3 & 4.29 \\
$26-30$ & 16 & 22.86 \\
$31-35$ & 31 & 44.29 \\
$36-40$ & 14 & 20.00 \\
$41-45$ & 5 & 7.14 \\
$45-50$ & 1 & 1.43 \\
\hline Mean Age=33.71+5.56 years
\end{tabular}


There were 66 patients $(94.29 \%)$ with azoospermia. The remaining $4(5.71 \%)$ had oligospermia, one patient with oligospermia was suspected to have tuberculous orchitis (Table 2).

Serum levels of the other three hormones expected to be evaluated in this group of patients were available for variable numbers of patients, as shown in the table The mean FSH value was 15.5 (range 2.42-56.4). The majority of the patients $(64.29 \%)$ had high FSH values $(>11 \mathrm{mIU} / \mathrm{ml})$ (Table 3).

Serum levels of the other three hormones expected to be evaluated in this group of patients were available for variable numbers of patients, as shown in the table The mean FSH value was 15.5 (range 2.42-56.4). The majority of the patients $(64.29 \%)$ had high FSH values $(>11 \mathrm{mIU} / \mathrm{ml})($ Table 4$)$.

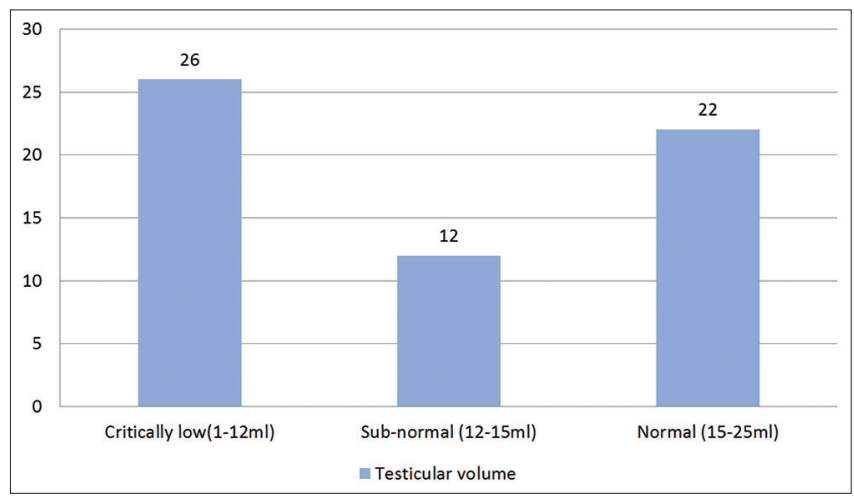

Figure 1: Testicular volume in studied cases

Table 2: Semen analysis in studied cases

\begin{tabular}{lcc} 
Semen analysis & Number of patients & Percentage \\
\hline Azoospermia & 66 & 94.29 \\
Oligospermia & 4 & 5.71 \\
\hline
\end{tabular}

\begin{tabular}{lccc}
\multicolumn{4}{l}{ Table 3: Hormonal assay in studied cases } \\
\hline Hormone & $\begin{array}{c}\text { Number of } \\
\text { patients }\end{array}$ & Range & Mean \\
& 70 & $2.42-56.4$ & 15.5 \\
\hline $\begin{array}{l}\text { FSH } \\
\text { (Normal 07-11.1 mlU/ml) }\end{array}$ & 1 & 5.5 & - \\
$\begin{array}{l}\text { LH } \\
\text { (Normal 0.8-7.6 IU/ml) }\end{array}$ & 5 & $201-691$ & 415.6 \\
$\begin{array}{l}\text { Testosterone } \\
\text { (Normal 33.8-106\%) }\end{array}$ & 6 & $4.6-12.5$ & 7.9 \\
$\begin{array}{l}\text { Prolactin } \\
\text { (Normal 2.5-17 ng/ml) }\end{array}$ & & & \\
\hline FSH: Follicle-stimulating hormone, LH: Luteinizing hormone &
\end{tabular}

Table 4: FSH levels in studied cases

\begin{tabular}{lcccc}
\hline FSH & Normal $($ mean 6.4) & & Elevated FSH levels (mean 21.8) \\
\hline FSH level $(\mathrm{mlU} / \mathrm{ml})$ & $0.7-11(\mathrm{mlU} / \mathrm{ml})$ & $11-20(\mathrm{mlU} / \mathrm{ml})$ & $20-30(\mathrm{mlU} / \mathrm{ml})$ & $>30(\mathrm{mlU} / \mathrm{ml})$ \\
Number of cases & 25 & 24 & 18 & 3 \\
\hline FSH: Follicle-stimulating hormone & & & &
\end{tabular}

The analysis of tubular number in testicular biopsy showed that all but one of our biopsies had an adequate number of seminiferous tubules (range 20-500, mean 78). In one patient whose biopsy was considered inadequate, only four tubules were seen. But still in that patient also the histopathological examination was done. The tubule diameter was assessed by morphometry and ranged from 44 to 487 microns (mean 216 microns). Basement membrane thickness was also evaluated by morphometry and ranged from 0.14 to 0.69 microns. The basement membrane was thickened (more than 0.40 microns) in 26 cases $(37.14 \%)$ and normal in $44(62.86 \%)$. The interstitium was normal in the majority of patients (75.71\%). Three biopsies showed epithelioid cell granulomata associated with lymphohistiocytic aggregates; acid-fast bacilli were not seen. One of these patients was suspected to have tuberculosis prior to the biopsy. In the other two, the granulomata were an incidental finding. In histological examination, maturation arrest was seen in $28(40 \%)$ patients and the most common stage at which maturation arrest was seen was found to be at the stage of primary spermatocyte (22.86\%) (Table 5, Figures 2 and 3).

In 11 biopsies hypospermatogenesis was seen. The number of cross-sections showing maturation up to mature spermatozoa was decreased; The number of mature spermatozoa found in each tubule was also markedly decreased to only one or two spermatozoa per tubule in $6 / 11$ cases $(9 \%)$, maturation extended only up to the spermatid stage, with only a few spermatids seen (Table 6).

These biopsies showed complete interruption of spermatogenesis in all tubules visualized in each cross section, uniformly. The maturation arrest was most frequently encountered at the level of primary spermatocytes $(57 \%)$. In the remaining $43 \%$, maturation arrest was encountered at the level of secondary spermatocytes and spermatogonia (Table 7).

Sertoli cells only pattern was seen in 20 biopsies (29\%) and was characterized by the complete absence of intratubular germ cells. The Sertoli cells were aligned perpendicular to the basement membrane. The cells were oval in shape and the nuclei were irregular or folded with prominent nucleoli. In most cases, the tunica propria and tubular basement membranes appeared normal, although in a few cases hyalinization was seen the interstitium contained varying numbers of Leydig cells. One case showed Leydig 


\section{Table 5: Major histological findings in testicular biopsy of studied cases}

\begin{tabular}{|c|c|c|c|c|}
\hline \multicolumn{3}{|c|}{ Testicular biopsy findings } & \multirow{2}{*}{$\begin{array}{c}\text { Number of cases } \\
52\end{array}$} & \multirow{2}{*}{$\begin{array}{c}\text { Percentage } \\
74.29\end{array}$} \\
\hline Tubular numbers & Adequate & $20-100$ & & \\
\hline & & $100-200$ & 15 & 21.43 \\
\hline & & $>200$ & 1 & 1.43 \\
\hline & Inadequate & $<20$ & 2 & 2.86 \\
\hline \multirow[t]{2}{*}{ Tubular diameter } & Normal & $(\geq 150 \mu)$ & 17 & 24.29 \\
\hline & Reduced & $(\leq 150 \mu)$ & 53 & 75.71 \\
\hline Basement & Normal & (0.3-0.4 microns) & 44 & 62.86 \\
\hline membrane (microns) & Thickened & ( $\geq 0.4$ microns $)$ & 26 & 37.14 \\
\hline Features of & Cellularity & Normal with lymphocytes & 53 & 75.71 \\
\hline \multirow[t]{7}{*}{ interstitium } & & Leydig cell clusters & 5 & 7.14 \\
\hline & & Leydig cell hyperplasia & 3 & 4.29 \\
\hline & & Granulomata & 3 & 4.29 \\
\hline & & Fibrosis & 3 & 4.29 \\
\hline & & Scant or absent with no fibrosis & 3 & 5.71 \\
\hline & Vascularity & Normal & 68 & 97.14 \\
\hline & & Thickened & 2 & 2.86 \\
\hline \multirow[t]{8}{*}{ Histology } & Seminiferous tubules & Normal spermatogenesis & 8 & 11.43 \\
\hline & & Hypospermatogenesis & 11 & 15.71 \\
\hline & & Maturation arrest & 28 & 40.00 \\
\hline & & Sertoli cell only & 21 & 30.00 \\
\hline & & Atrophy/Fibrosis & 2 & 2.86 \\
\hline & Maturation arrest at the stage of & Primary spermatocyte & 16 & 22.86 \\
\hline & & Secondary spermatocyte & 3 & 4.29 \\
\hline & & Spermatogonia & 9 & 12.86 \\
\hline
\end{tabular}

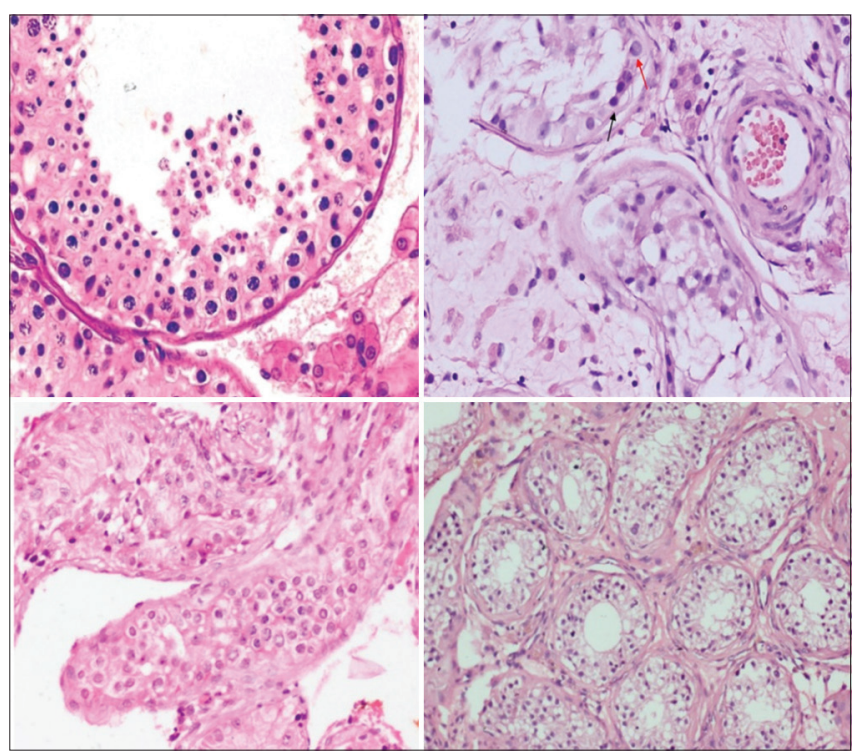

Figure 2: Biopsy findings (Clockwise from left upper corner) Hypospermatogenesis showing occasional mature spermatozoa, Maturation arrest at the level of spermatogonia (black arrow - spermatogonia A, red arrow - spermatogonia B), Maturation arrest at the level of primary spermatocyte, and Maturation arrest at the level of secondary spermatocyte

cell clusters and three showed Leydig cell hyperplasia. The others did not show any prominence of these cells (Table 8).

Peritubular fibrosis and atrophy were seen in $2(3 \%)$ cases, one which showed complete atrophy of tubules with no intratubular germ cells and associated fibrosis of the interstitium. The other case showed a few scattered Leydig cells in the interstitium (Table 9).
The chromosomal analysis of the studied cases showed that only one patient, a 23-year-old male had an abnormal karyotype. This male patient who had a normal phenotype had 45 chromosomes with loss of the $\mathrm{Y}$ chromosome and only one X chromosome - a 45, X male. This patient had a critically low testicular volume of $8 \mathrm{ml}$; his serum FSH showed a normal value of $8.79 \mathrm{mIU} / \mathrm{ml}$. One homolog of chromosome 1 showed an additional band at the terminal end of its long (q) arm. In view of the presence of the testis, a detailed cytogenetic analysis was done using FISH probes for the SRY gene on the short (p) arm of chromosome Y, the centromeres of the $\mathrm{X}$ and $\mathrm{Y}$ chromosomes, and the heterochromatin region of the Y chromosome. Metaphase FISH analysis confirmed that the SRY gene was added to the terminal end of chromosome $1 \mathrm{q}$ (qter). No other $\mathrm{Y}$ chromosome material could be seen. The presence of the SRY gene conferred the male phenotype even though his karyotype showed only one sex chromosome, the $\mathrm{X}$ chromosome. Y chromosomal microdeletion study was done in 24 patients, 21 of whom did not show deletions of the AZFa, b, or c loci. Three patients showed deletions. Two patients had deletions of the AZFb region only. The third was the 45, X male who showed absence of all three AZF loci, as expected because these loci are present on the long arm of the Y chromosome, which was absent in him (Table 10).

Testicular biopsy in both patients with the AZFb microdeletion showed maturation arrest, one at the level of primary spermatocytes and the other at the level of spermatogonia. Testicular biopsy of the $45, \mathrm{X}$ male who 


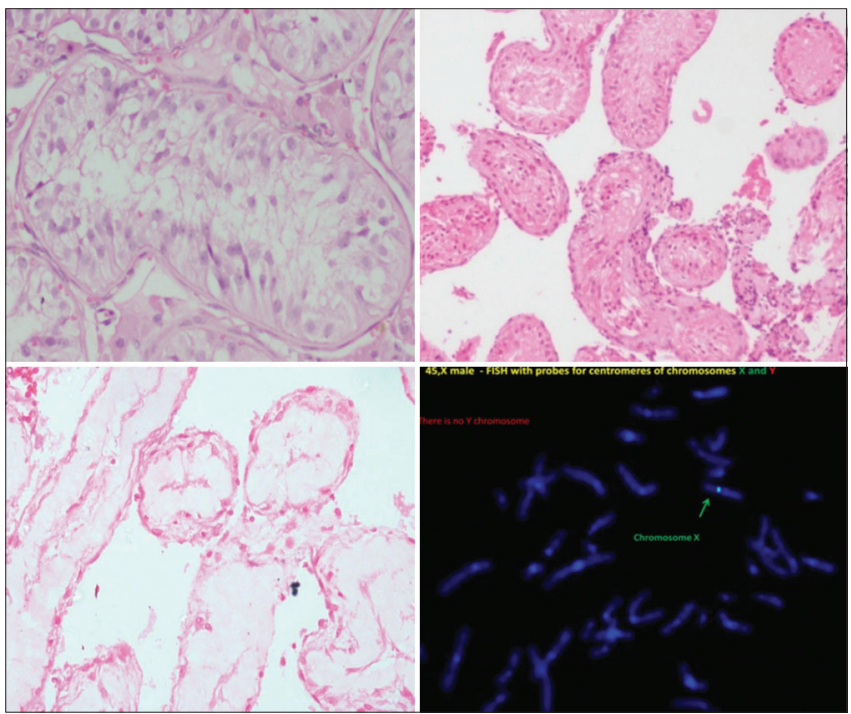

Figure 3: (Clockwise from left upper corner) Sertoli cells only, Atrophy of seminiferous tubules, Peritubular fibrosis, and FISH probe showing absence of signal for the $\mathrm{Y}$ chromosome. FISH: Fluorescence in situ hybridization

\begin{tabular}{|c|c|c|c|c|c|}
\hline $\begin{array}{l}\text { S. } \\
\text { No. }\end{array}$ & Age & $\begin{array}{c}\text { Test } \\
\text { Volume }\end{array}$ & FSH & Karyotype & Y Chromosome \\
\hline 1. & 33 & 13.5 & 6.2 & --- & --- \\
\hline 2. & 29 & 12.5 & 6.8 & --- & --- \\
\hline 3. & 31 & 12 & 7.4 & --- & --- \\
\hline 4. & 43 & 14 & 22.8 & --- & --- \\
\hline 5. & 38 & 13 & 12.6 & --- & --- \\
\hline 6. & 31 & 15 & 6.83 & --- & --- \\
\hline 7 & 29 & 10 & 16.6 & --- & --- \\
\hline 8. & 36 & 13 & 6.46 & --- & --- \\
\hline 9. & 29 & 15 & 8.46 & $46, X Y$ & Negative \\
\hline 10. & 41 & 12 & 14.2 & $46, X Y$ & Negative \\
\hline 11. & 35 & 13 & 15.8 & $46, X Y$ & Negative \\
\hline
\end{tabular}

had microdeletions involving AZFa, b, and c loci, showed Sertoli cell only morphology (Table 11).

\section{DISCUSSION}

Nearly $15-20 \%$ of Indian married couples are evaluated for infertility. Causes for female infertility are often the main focus, particularly in our society. The male causes are often neglected or ignored due to the social stigma associated with it. However, statistics prove that in nearly $30 \%$ of the cases, the cause of infertility rests with the male partner and in 10\% both the male and female have abnormalities. ${ }^{11}$

Male infertility could be due to obstructive and nonobstructive causes. Obstruction during the transit of the viable sperms from the seminiferous tubules, to reach the ejaculate, causes azoospermia. This implies that normal sperms are present in the testicular tissue. The obstructive causes of azoospermia signify that there is no fault with process or apparatus of spermatogenesis. However, during the transit of the viable sperms from the seminiferous tubules, there is a focus of blockage, preventing them from becoming a part of the ejaculate. This implies that there is viable sperm in the testicular tissue to work with, and all that is then required is their medical extraction. ${ }^{12}$ This holds promise for the couple seeking help. Among the non-obstructive causes, the problem could be varied. The range of causes can be from anti-sperm antibodies to abnormalities with the intrinsic infrastructure or the mechanism of spermatogenesis. The latter can be due to the various histological pictures described earlier in which the cellularity of not only the seminiferous tubules but also of the supporting system can affect spermatogenesis. ${ }^{13}$

The majority of our patients ( $88 \%$ ) had abnormal testicular morphology. All the histological patterns associated with infertility were seen in our series, namely Sertoli cell only, maturation arrest, hypospermatogenesis, seminiferous tubule hyalinization, and normal spermatogenesis. Normal spermatogenesis was seen in $12 \%$ of our patients which included three of the four with oligospermia. Among those with abnormal morphology, the majority (40\%) fell under the category of maturation arrest. This finding was similar to the report of a meta-analysis performed by McLachlan et al., of Australia in 2012. The cohort of patients included those from various centers across Australia and one center in Denmark. ${ }^{14}$

Maturation arrest was further subclassified based on the level at which the arrest occurred. Primary spermatocytes were the most common finding in most of our biopsies in $23 \%$ among the total number of cases. On comparison of this parameter with the study McLachlan et al., the percentage of cases with primary spermatocytes was only $10.1 \%$. This may be attributed to the fact that his series had a significant number of biopsies with mixed pattern, in which also the cases with primary spermatocytes was $10 \%$.

It was interesting to note that three of our patients were noted to have granulomatous inflammation on histological evaluation. This was the reason for the azoospermia. However, it was also noted that in all three patients, normal spermatogenesis was also found in the same biopsy. Therefore, the azoospermia was both treatable and reversible. It was suggested that the etiology may be tuberculosis, as this is the most common cause for granulomatous inflammation in India. Serological tests were negative for syphilis. When we compared our findings to other studies from India, and other countries, such as 


\begin{tabular}{|c|c|c|c|c|c|c|}
\hline S. No. & AGE & TEST VOL & FSH & LEVEL OF ARREST & KARYOTYPE & Y CHR DELN \\
\hline 1. & 29 & 0.13 & 0.12 .12 & Primary spermatocyte & . & . \\
\hline 2. & 29 & 20 & 28.6 & Primary spermatocyte & & \\
\hline 3. & 34 & 13 & 13.7 & Primary spermatocyte & $46, X Y[40]$ & Negative \\
\hline 4. & 32 & 12 & 15.9 & Primary spermatocyte & & \\
\hline 5. & 35 & 15 & 2.58 & Primary spermatocyte & $46, X Y[20]$ & Zab \\
\hline 6. & 33 & 1.5 & 2.38 & Primary spermatocyte & $46, X Y[20]$ & Negative \\
\hline 7. & 32 & 15 & 4.79 & Primary spermatocyte & . & . \\
\hline 8. & 37 & 15 & 27.5 & Primary spermatocyte & . & . \\
\hline 9. & 25 & 20 & 4.09 & Primary spermatocyte & . & . \\
\hline 10. & 39 & 12 & 3.02 & Primary spermatocyte & . & . \\
\hline 11. & 27 & 10 & 20.8 & Primary spermatocyte & . & . \\
\hline 12. & 30 & 15 & 21 & Primary spermatocyte & $46, X Y[25]$ & Negative \\
\hline 13. & 34 & 11 & 21.6 & Primary spermatocyte & . & . \\
\hline 14. & 26 & 9 & 25.1 & Primary spermatocyte & . & . \\
\hline 15. & 33 & 10 & 16 & Primary spermatocyte & . & . \\
\hline 16. & 26 & 12 & 13.8 & Primary spermatocyte & 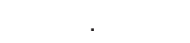 & \\
\hline 17. & 37 & 10 & 14.7 & Secondary spermatocyte & $46, X Y[20]$ & Negative \\
\hline 18. & 35 & 12 & 7.86 & Secondary spermatocyte & . & . \\
\hline 19. & 35 & 13 & 4.85 & Secondary spermatocyte & $46, X Y[20]$ & Negative \\
\hline 20. & 31 & 20 & 2.43 & Spermatogonia & . & . \\
\hline 21. & 36 & 7.5 & 4.86 & Spermatogonia & $46, X Y[20]$ & Zab \\
\hline 22. & 28 & 7.8 & 0.14 & Spermatogonia & . & . \\
\hline 23. & 36 & 10 & 13 & Spermatogonia & . & . \\
\hline 24. & 36 & 10 & 25.1 & Spermatogonia & . & Negative \\
\hline 25. & 36 & 10 & 11 & Spermatogonia & . & . \\
\hline 26. & 45 & 15 & 13.2 & Spermatogonia & . & . \\
\hline 27. & 32 & 13 & 4.65 & Spermatogonia & $46, X Y[20]$ & Negative \\
\hline 28. & 31 & 9 & 18.3 & spermatogonia & $46, X Y[20]$ & Negative \\
\hline
\end{tabular}

\begin{tabular}{|c|c|c|c|c|c|}
\hline $\begin{array}{l}\text { S. } \\
\text { No. }\end{array}$ & AGE & TEST VOL & FSH & KARYOTYPE & Y CHR \\
\hline 1. & 27 & 13 & 12.6 & & \\
\hline 2. & 29 & 20 & 13.5 & $46, \mathrm{XY}[20]$ & Negative \\
\hline 3. & 33 & 12 & 44.5 & & \\
\hline 4. & 32 & 12.5 & 14.5 & $46, \mathrm{XY}[20]$ & Negative \\
\hline 5 & 25 & 10 & 9.96 & $46, X Y[20]$ & Negative \\
\hline 6. & 41 & 10 & 10.8 & . & . \\
\hline 7. & 31 & 14 & 35 & . & \\
\hline 8. & 35 & 12 & 5.13 & . & . \\
\hline 9. & 37 & 12 & 23.6 & & \\
\hline 10 & 32 & 15 & 18.6 & $46, \mathrm{XY}[20]$ & Negative \\
\hline 11. & 37 & 8 & 15.2 & $46, \mathrm{XY}[45]$ & Negative \\
\hline 12. & 33 & 10 & 8.97 & & \\
\hline 13. & 47 & 10 & 27.3 & $46, X Y[20]$ & Negative \\
\hline 14 & 31 & 12 & 26.6 & $46, X Y[20]$ & Negative \\
\hline 15. & 30 & 13 & 14.4 & & \\
\hline 16. & 31 & 11 & 26.6 & $46, X Y[20]$ & Negative \\
\hline 17. & 43 & 15 & 56.4 & . & \\
\hline 18. & 23 & 8 & 8.79 & $\begin{array}{c}45, X \\
\text { add1q44[25] }\end{array}$ & $\begin{array}{l}\text { AZFa, } \\
b, c\end{array}$ \\
\hline 19. & 39 & 9 & 15.5 & & \\
\hline 20. & 31 & 10 & 26.6 & 46, XY[20] & Negative \\
\hline
\end{tabular}

FSH: Follicle-stimulating hormone

$45 X$, add $1944^{[25]}: 45 X$ karyotype with additional chromosomal material of unknown origin AZFa, b, c : azoospermia factor- a, b and c microdeletions

Egypt, Saudi Arabia and England, we noted that there was no distinct pattern that could be delineated. This suggests that a variety of histological patterns may be associated with male infertility. The most common histopathological abnormality among the evaluated Egyptian patients was Sertoli cell only as reported by Rashed et al., ${ }^{15}$ which was also the case in the study conducted by Al Al-Rayess and Al-Rikabi ${ }^{16}$ On the other hand, in a study conducted by Meinhard et al., the highest percentage of patient in had diagnosis of hypospermatogenesis. ${ }^{17}$

When our study was compared to other studies from across India, the findings were again variable, with no distinct patterns being identified. In a study by Parikh et al., ${ }^{18}$ the most prominent category was normal spermatogenesis. In the study by Purohit et al., ${ }^{19}$ two categories were equally significant, namely Sertoli cells only and hypospermatogenesis.

In our study cytogenetic analysis was normal in 23 patients. On patient was a male with 45 chromosome $\mathrm{X}$ with no visible y chromosome, Klinefelter Syndrome which is the most common genetic abnormality of sexual development usually seen, but was not found in our series of karyotypes. In a large study conducted by Punab et al., the authors reported the sex chromosome abnormalities in $4.1 \%$ of cases of severe male factor infertility. Same study reported $\mathrm{Y}$ chromosome microdeletions in $2.3 \%$ of the studied cases. $^{20}$ 


\begin{tabular}{|c|c|c|c|c|c|}
\hline S. No. & AGE & TEST VOL & FSH & KARYOTYPE & Y CHR \\
\hline 1. & 37 & 10 & 10.2 & . & . \\
\hline 2. & 29 & 9 & 15.3 & . & . \\
\hline
\end{tabular}

\begin{tabular}{|c|c|c|c|}
\hline & Karyotype & $\begin{array}{l}\text { Number } \\
\text { of cases }\end{array}$ & Percentage \\
\hline \multirow{2}{*}{$\begin{array}{l}\text { Chromosomal } \\
\text { numbers }\end{array}$} & Normal - 46, XY & 23 & 95.83 \\
\hline & $\begin{array}{l}\text { Abnormal - } 45, X \\
\text { male }\end{array}$ & 1 & 4.17 \\
\hline \multirow{4}{*}{$\begin{array}{l}\text { Y } \\
\text { Chromosomal } \\
\text { Microdeletion }\end{array}$} & Negative & 21 & 87.50 \\
\hline & Positive & & \\
\hline & AZFb deletion & 2 & 8.33 \\
\hline & AZFa, b, c deletion & 1 & 4.17 \\
\hline
\end{tabular}

\begin{tabular}{|c|c|c|}
\hline Histology & $\begin{array}{l}\text { Y chromosome } \\
\text { microdeletion }\end{array}$ & Karyotype \\
\hline Primary spermatocyte & AZFb & $46, X Y$ \\
\hline Spermatogonia & $\mathrm{AZFb}$ & $46, X Y$ \\
\hline Sertoli cell only & AZFa, b, c & $\begin{array}{c}45, \mathrm{X}, \operatorname{der}(1) \mathrm{t}(\mathrm{Y} ; 1) \\
(\mathrm{p} 11.2 ; \mathrm{q} 44)\end{array}$ \\
\hline
\end{tabular}

Limitations of the study

All patients evaluated for infertility did not have all the serum hormone levels assessed, namely LH, testosterone, and prolactin levels. The genetic analysis had not been done in all patients who had biopsies.

\section{CONCLUSION}

Testicular biopsy is one of the important investigations in the evaluation of patients with male factor infertility and can be very helpful in the management of these patients. Genetic studies such as chromosomal analysis and Chromosomal microdeletion studies can be helpful in further investigating these patients if definite diagnosis can not be established on the basis of testicular biopsy. Testicular biopsies can also be used for sperm extraction for usage in in vitro fertilization and intracytoplasmic sperm injection.

\section{ACKNOWLEDGMENT}

The authors acknowledge assistance of Department of General Pathology, Christian Medical College, Vellore in undertaking this study.

\section{REFERENCES}

1. Miyamoto $T$, Tsumura A, Miyagawa $\mathrm{Y}, \mathrm{Koh} \mathrm{E}$, Namoki $\mathrm{M}$ and Sengoku K. Male infertility and its causes in human. Adv Urol. 2012;2012:384520.

https://doi.org/10.1155/2012/384520

2. Wong TW, Straus FH, Jones TM and Warner NE. Pathological aspects of the infertile testis. Ural Clin NorthAm. 1978;5(3):503-530.

3. Witchel SF. Disorders of sex development. Best Pract Res Clin Obstet Gynaecol. 2018;48:90-102.

https://doi.org/10.1016/j.bpobgyn.2017.11.005

4. Barratt CL, Björndahl L, De Jonge CJ, Lamb DJ, Martini FO, McLachlan R, et al. The diagnosis of male infertility: An analysis of the evidence to support the development of global WHO guidance-challenges and future research opportunities. Hum Reprod Update. 2017;23(6):660-680.

https://doi.org/10.1093/humupd/dmx021

5. Cao $Y$, Cao $X$ and Han J. Percutaneous testicular sperm aspiration and intracytoplasmic sperm injection in the treatment of severe male infertility. Zhonghua Fu Chan Ke Za Zhi. 2001;36(11):666-668.

6. Dabaja AA and Schlegel PN. Microdissection testicular sperm extraction: An update. Asian J Androl. 2013;15(1):35-39.

https://doi.org/10.1038/aja.2012.141

7. Huang JY and Rosenwaks Z. Assisted reproductive techniques. Methods Mol Biol. 2014;1154:171-231.

https://doi.org/10.1007/978-1-4939-0659-8_8

8. Schoor RA, Elhanbly S, Niederberger CS and Ross LS. The role of testicular biopsy in the modern management of male infertility. J Urol. 2002;167(1):197-200.

9. Al-Hussain $\mathrm{T}$, Bakshi $\mathrm{N}$ and Akhtar $\mathrm{M}$. Intratubular germ cell neoplasia of the testis: A brief review. Adv Anat Pathol. 2015;22(3):202-212

https://doi.org/10.1097/PAP.0000000000000066

10. Rosellen J, Steffens J and Kranz J. Testikuläre Spermienextraktion bei männlicher Infertilität: Indikationen, Erfolgsraten, praktische Durchführung und mögliche Komplikationen [Testicular sperm extraction in male infertility: Indications, success rates, practical implementation, and possible complications]. Urologe A. 2021;60(7):921-931.

https://doi.org/10.1007/s00120-021-01480-1

11. Deshpande PS and Gupta AS. Causes and prevalence of factors causing infertility in a public health facility. J Hum Reprod Sci. 2019;12(4):287-293.

https://doi.org/10.4103/jhrs.JHRS_140_18

12. Wosnitzer MS and Goldstein M. Obstructive azoospermia. Urol Clin North Am. 2014;41(1):83-95.

https://doi.org/10.1016/j.ucl.2013.08.013

13. Abdullah $L$ and Bondagji $N$. Histopathological patterns of testicular biopsy in male infertility: A retrospective study from a tertiary care center in the western part of Saudi Arabia. Urol Ann. 2011;3(1):19-23.

https://doi.org/10.4103/0974-7796.75867

14. McLachlan RI, Rajpert-De Meyts E, Hoei-Hansen CE, de Kretser DM and Skakkebaek NE. Histological evaluation of the human testis--approaches to optimizing the clinical value of the assessment: Mini Review. Hum Reprod. 2006;22(1):2-16. https://doi.org/10.1093/humrep/del279

15. Rashed MM, Ragab NM, Shalaby AR and Ragab WK. Patterns of testicular histopathology in men with primary infertility. Internet 
J Urol. 2008;2(5):1-4.

16. Al-Rayess MM and Al-Rikabi AC. Morphologic patterns of male infertility in Saudi patients. A University Hospital experience. Saudi Med J. 2000;21(7):625-628.

17. Meinhard E, McRae CU and Chisholm GD. Testicular biopsy in evaluation of male infertility. Br Med J. 1973;3(5880):577-581. https://doi.org/10.1136/bmj.3.5880.577

18. Parikh UR, Goswami HM, Deliwala KJ, Shah AM and Barot HP. Testicular biopsy in male infertility: Study of 80 cases. Int $\mathrm{J}$
Pathol. 2012;25(2):75-77.

19. Purohit TM, Purohit MB and Dabhi BJ. Study of semen analysis and testicular biopsy in infertile male. Indian J. Pathol. Microbiol. 2004;47(4):486-490.

20. Punab M, Poolamets O, Paju P, Vihljajev V, Pomm K, Ladva R, et al. Causes of male infertility: A 9-year prospective monocentre study on 1737 patients with reduced total sperm counts. Hum. Reprod. 2017;32(1):18-31.

https://doi.org/10.1093/humrep/dew284

Author's Contribution:

PB-Concept and design of the study, prepared first draft of manuscript, Interpreted the results; reviewed the literature and manuscript preparation;

VMS- Concept, coordination, statistical analysis and interpretation, preparation of manuscript and revision of the manuscript

Work attributed to:

Department of General Pathology, Christian Medical College, Vellore, Tamil Nadu, India

\section{Orcid ID:}

Priscilla Babu - (10) https://orcid.org/0000-0002-8075-1589

Vivi M Srivastava - (i) https://orcid.org/0000-0001-6404-3622 